$$
\text { OONF-ODOBO1--34 }
$$

\title{
COMMERCIAL AIRCRAFT FUEL EFFICIENCY POTENTIAL THROUGH 2010
}

\author{
$\mathrm{CONF}-900801--34$
}

DE91 000720

\author{
David L. Greene
}

Oak Ridge National Laboratory

Oak Ridge, Tennessee 37831-6207

\section{ACKNOWLEDGEMENTS}

Space does not permit me to acknowledge by name the many individuals in the aircraft industry and government whose help was essential to this study.

\section{ABSTRACT}

Aircraft are second only to motor vehicles in the use of motor fuels, and air travel is growing twice as fast. Since 1970 air travel has more than tripled, but the growth of fuel use has been restrained by a near doubling of efficiency, from 26.2 seat miles per gallon (SMPG) in 1970 to about 49 SMPG in 1989. This paper explores the potential for future efficiency improvements via the replacement of existing aircraft with "1990"s generation" and "post 2000" aircraft incorporating advances in engine and airframe technology. Today, new commercial passenger aircraft deliver 50.70 SMPG. New aircraft types scheduled for delivery in the early 1990's are expected to achieve 65-80 SMPG. Industry and government researchers have identified technologies capable of boosting aircraft efficiencies to the 100-150 SMPG range. Under current industry plans, which do not include a post-2000 generation of new aircraft, the total aircraft fleet should reach the vicinity of 65 SMPG by 2010. A new generation of 100-150 SMPG aircraft introduced in 2005 could raise the fleet average efficiency to $75-80$ SMPG in 2010. In any case, fuel use will likely continue to grow at from 12\%/yr. through 2010.

\section{INTRODUCTION}

Aircraft are second only to highway vehicles as consumers of motor fuels, and demand for air travel is grnwing nearly twice as fast as travel by highway vehicles. Since the early 1970's, air transport has doubled its energy efficiency by means of improved technology and operations. Even with this improvement, energy use by commercial air carriers grew at an average annual rate of $2 \%$ from 1970 to 1987.

This paper reviews the potential for further aircraft efficiency improvements through the year 2010. Its purpose is to define the range of future commercial aircraft fleet efficiency improvements, from what seems likely given existing trends and plans, to the maximum achievable given existing technology and the rate of aircraft stock turnover. The first step is to determine the efficiencies of existing aircraft types and develop estimates for the next generation of aircraft to be delivered in the early 1990's. Next fuel efficiency technologies are identified, as well as estimates of their impacts. The potential impact on fleet fue! efficiency is then evaluated, using four scenarios to describe what is likely to happen and what is possible with aggressive improvements to existing and future aircraft.

\section{COMMERCLAL AIRCRAFT ENERGY USE AND EFFICIENCY, 1970-1988}

Energy use by jet aircraft today would be far higher without the dramatic efficiency improvements achieved over the past 20 years. Since 1970, passenger traffic in the U.S. has more than tripled, increasing at an average annual rate of $6.6 \%$. At the same time, energy use increased only $43 \%$, an average annual rate of just over $2 \%$. More seats per aircraft, higher load factors, improved engine efficiencies and aerodynamics almost doubled SMPG efficiencies. SMPG improved from 26.2 in 1970 to 31.1 SMPG by 1975 and reached 45.6 SMPG in 1987 [2]. Current generation, new aircraft deliver approximately 50-70 SMPG.

Available seats per aircraft have increased from 111 in 1970 to 148 in 1980 , and 161 in 1987 [2]. Industry analysts foresee continued growth in the size 
of aircraft as a necessary means of increasing passenger capacity without worsening airport traffic congestion $[1,7]$. The Federal Aviation Administration (FAA) predicts that by 2010, the average airplane will seat 200 passengeis [16]. Passenger load factors, the percent of available seats occupied by paying passengers, have grown from $49.7 \%$ in 1970 to $59.7 \%$ in 1980 , and stood at $62.3 \%$ in 1987 [2]. The FAA foresees a continued improvement in load factors, reaching $65.8 \%$ by 2000 [17]. Energy use per available seat mile also improved because larger, more efficient aircraft replaced older ones. As early as 1980, the switch to more efficient aircraft was saving more fuel than any other single factor [13]. Despite today's low energy prices, aircraft fleet efficiency will continue to improve as newer, more efficient engines and airframes replace older, less efficient equipment.

\section{TECHNOLOGICAL POTENTIA: TO IMPROVE COMMERCIAL AIRCRAFT ENERGY EFFICIENCY}

The National Acronautics and Space Administration established R\&D goals for commercial subsonic transport aircraft that call for major fuel economy improvements [5]: reduce drag by $15-20 \%$, reduce weight $15-2.5 \%$, and reduce the specific fuel consumption of jet engines by $20-30 \%$. Achieving these goals will demand major improvements to engines and aerodynamics and will require significant advances in structural materials for airframes and high-temperature materials for engine components. Advances in the use of supercomputers for design and control of aircraft and operations will also be necessary.

Engines Since its introduction in commercial aircraft in the 1960's, the jet engine has evolved from turbojet to turbofan to high bypass turbofan, with ever increasing efficiency. Of the $80 \%$ theoretical efficiency improvement available in the original turbojet designs, half $(40 \%)$ has been realized in current high bypass turbofan designs [11]. Higher thermodynamic engine efficiencies have also been realized by use of improved materials that allow higher turbine inlet temperatures (up to $1850 \mathrm{~K}=$ 2870F), improvements in compressors permitting higher overall pressure (up to 4():1, [11]), and numerous refinements in components to reduce friction and improve the aerodynamics of compressor and fan blade designs.

A major propulsion efficiency advance can be realized with Ultra High Bypass (UHB) engines that boost the bypass ratio from current levels of 6 to 7 up to 15 to 20. Ducted UHB turbofans have been shown to yield efticiency improvements of $10-20 \%$ $[11,12,13]$. Unducted, or propfan engines using advanced propeller designs have been demonstrated to achieve $20-30 \%$ efficiency increases over current turbofan engines. Advanced propeller designs using twin counter-rotating propellers have overcome the previous speed limitations of turboprops, enabling aircraft to achieve Mach .8 to .9 with propfans [13]. The advanced unducted fan engines deliver $30 \%$ greater fuel economy, but cost twice as much $(\$ 10$ million versus $\$ 5$ million per $\$ 30-40$ million aircraft) as present generation high bypass engines $[9,19]$.

Improvements in the thermodynamic efficiency of the core turbine engines depend directly on the development of advanced, high-temperature materials. Advanced ceramic and metal matrix composite materials will be necessary to increase turbine inlet temperatures the $500^{\circ} \mathrm{F}$ or more required for another $20 \%$ increase in efficiency [13]. Material advances will also be essential to increasing overall pressure ratios to $100: 1$, reducing the need for airfoil cooling, and reducing sverall engine weight. Until 1960,60\% of the weight of aircraft turbine engines was steel. Steel is now less than $20 \%$, due to the use of nickel and titanium alloys that comprise $65 \%$ of the weight of current generation engines. To achieve the efficiency goals of advanced engine concepts, it is projected that $60 \%$ of the weight of advanced engines will be metal matrix and ceramic matrix composites. At present, these materials still suffer from brittleness and sensitivity to flaws that prohibit their use [11j. Airframe Future airframe efficiency improvements will require reductions in aerodynamic drag and airframe weight.

Advances in supercomputing technology have allowed computational fluid dynamics to become a major tool for airframe and engine design. Continuing advances in supercomputer hardware and computing software will make it possible to simulate airflow around wings, fuselage, and engine mounts with increasing detail, accuracy, and speed. This will permit greater optimization of aerodynamics in all aspects of airframe design.

At low speeds, airflow over an airfoil (wing) takes place in smooth layers (laminar flow). As speeds increase, a greater fraction of the airflow becomes turbulent, greatly increasing drag. Laminar flow control concepts attempt to maintain low-drag, laminar flow over the aircraft's wings at cruising speeds. Passive, or natural, laminar flow attempts to design shapes and use sinooth surfaces to minimize turbulence. Active concepts utilize suctior on key 
wing surfaces to smooth the airflow, and change wing shapes to adapt to changes in speed, altitude, and weight. Most promising are itybrid concepts that include grooves in the portion of the wing in iront of the spar, through which air is vacuumed to reduce turbulence, with ultra-smooth wing surfaces behind to maximize the area of naturally laminar flow [14]. Although in many respects laminar flow control is still a subject of basic research, "smart wing" concepts will be introduced in the early 1990's. Airbus' new A 340 and A330 models will include variable camber wings that adapt their profiles automatically during flight to match changes in weight, speed, and altitude [4].

NASA has researched various concepts for reducing the drag caused by large eddies produced by aircraft fuselage [3]. Considerable theoretical and simulation research is still needed before manufacturers will attempt to implement these concepts.

Lightweight composite materials have the potential to reduce airframe weight by $30 \%$ with equal or better siructural strength. Today's planes are $9 \% \%$ metallic, with composites used for a very limited number of components, such as vertical fins and horizontal surfaces of tailplanes [12]. Airframes of the 1990's may be only $75 \%$ metallic as composites are increasingly used. In the next century, some foresee advances that could enable planes to be $80 \%$ composites and 30\% lighter [14].

Operations As airport congestion increases with increasing air traffic, airlines will respond by using larger planes. Beyond 1995, Boeing expects more than half of the seats they produce to be in aircraft of 350 seats or more, and two thirds of the aircraft they sell to have more than 170 seats. Today nearly two thirds have under 170 seats. The trend towards larger aircraft will increase average fleet fuel economy.

Greater airport congestion will also require improved tools for planning and control of airport operations. Automated tools for flight planning, airport operations planning, and air traffic control will become increasingly sophisticated at optimizing the air transport system. Improved flight planning, for example, could reduce fuel use by $6 \%$ [20]. There will also be increased pressure for policies to regulate the peaking of demand for congested airport facilities. Although significant airport and air traffic operations improvements are possible, such improvements may be required merely to hold airport celays constant, given the expected increases in air traffic $[10,20]$.
Super and Hypersonic Aircraft Though not specifically considered in this report, supersonic flights could become an important air passenger market by 2010. Perhaps more importantly, because speed defines the frontier of commercial air techrology, $R \& D$ in this area is likely to generate technological advances for subsonic aircraft as well.

Supersonic aircraft require many of the same technological advances as subsonic aircraft, but their needs are greater. The importance of aerodynamics to drag at speeds of Mach 2 to 5 is clear. It is also important to holding down the surface temperatures on wings and inside engines. This places additional requirements on airframe and engine materials. Speed also creates a need for fuels with greater thermal stability, faster reaction rates, and greater capability to absorb heat than traditional kerosene-type hydrocarbons [8]. It may be possible to make hydrocarbon fuels usable at speeds of Mach 3-4 by removing most of the free oxygen to enhance their thermal stability, Beyond this, cryogenic methane may be usable at speeds of Mach 4 to 5 . At speeds in the vicinity of Mach 8 and beyond, hydrogen's high reaction rate and its ability to serve as a heat sink for the engine, reducing the cooling requirements, may make it the only choice [15].

At super to hypersonic speeds, the turbofan engine will not function. At least half a dozen new engine concepts are under consideration that atternpt to offer turbofan-like performance for take-off and landing, and turbojet or rocket engine-like performance for cruising. Because these concepts lack the propulsion efficiency benefits of the turbofan engine, a premium is placed on thermodynamic efficiency. This means higher temperatures $(3500 \mathrm{~F}$ or more) and compression ratios (100:1 or greater), which implies still more demanding requirements for engine materials. Such improvements could produce an engine $40 \%$ more efficient than current supersonic technology [8].

Overall SMPG Improvement Potential Efficiency improvement estimates for the technologies described above are summarized in Table 1. Figure 1 graphically summarizes the range of estimates for each technology. All the estimates shown are relative to 1990 's generation aircraft, such as the Airbus 320 , 330, and 340 models and McDonnell Douglas' MD. 11 and MD-90 series aircraft. In making efficiency improvement estimates for new aircraft, we will use the median percent SMPG improvements shown in Table 1, and assume that percent improvements are additive. Propfan engines are limited in the amount of thrust they can generate due to physical constraints on the size of the external fan. Thus, 
they will be limited to narrow-body aircraft, or to wide-body aircraft with more than two engines.

Using the median efficiency improvement estimates gives an overall SMPG improvement for propfans of $82 \%$ and for ultra-high bypass engines of $53 \%$. For comparison, the minimum and maximum estimates give $60 \%$ and $104 \%$ for propfans, and $46 \%$ and $94 \%$ for ultra-high bypass ducted fans, respectively.

\section{COMMERCIAL AIRCRAFT EFFICIENCY ESTIMATES}

Through 1984, the U.S. Department of Transportation published data sufficient to estimate SMPG by aircraft type for all major commercial air carriers [18]. Since then SMPG data for individual aircraft types have become generally unavailable. Estimates of efficiencies for existing aircraft, for planned and designed but not-yet-introduced aircraft, and for yet-to-be-designed, post-2000 aircraft were derived from various sources as documented in Greene [6].

It should be possible to double the SMPG efficiency of the current generation commercial aircraft (-igure 2). Technologically achievable efficiencies for post-2000 aircraft are estimated at between 110 and 150 SMPG. The least efficient is the 2-Engine Wide Body class, because this class will probably not be able to use propfans due to thrust limitations. All other classes are assumed to be using propfans as the standard engine. No new 3 and 4-Engine Narrow Body aircraft have been defined. Manufacturers are not introducing new aircraft of these types in the 1990's, and the continued upsizing of aircraft capacity makes it unlikely that 3- and 4- Engine Narrow Bodies will be introduced post-2000 either. Whether or not manufacturers actually introduce such aircraft and airlines actually buy them will depend on a great many factors, especially jet fuel prices. Some have claimed that jet fuel prices must exceed $\$ 1.00 /$ gal. to make propfans economical [9]. Others do not believe that propfans will ever be applied to medium and large aircraft. These analysts cite expensive maintenance due to the greater number of moving parts, higher initial cost, blade containment problems, and noise as reasons why propfans will be limited to small (150 seats or less) aircraft.

In the long run, we can expect commercial aircraft efficiencies to more than double, as the current fleet which gets about 50 SMPG is retired and replaced with models achieving 110-150 SMPG.
This evolution will take time, however, perhaps half a century. Aircraft lifetimes are typicaliy 25-30 years [16], and a new generation of aircraft will not be introduced for at least 10 years, and probably more. Furthermore, if fuel prices remain low there will be little incentive to design, test, and market such aircraft.

\section{PROJECTED STOCK EFFICIENCY IMPROVEMENTS}

In this section, we project the likely evolution of the efficiency of the commercial airline fleet. The influence of two key factors is considered: introducing a new generation of post-2000 aircraft, and upgrading of existing fleet efficiencies via retrofitting and operational improvements.

Given a forecast of aircraft in operation by type, we can apply the estimated SMPG efficiencies by type, together with estimated usage rates and seating capacities to compute fleet energy use and efficiency. The cornerstone of the forecasts is the forecast of airline fleet composition by aircraft type. An FAA forecast of the U.S. airline fleet composition through 2010 formed the basis of the projection [16]. The forecast predicts a $1.9 \%$ annual rate of increase in aircraft stock through 2010, a $53 \%$ increase overall. By $2010,98 \%$ of the aircraft in operation are current generation or 1990's generation aircraft. No post2000 generation aircraft are assumed. L.oad factors are assumed to increase frnm $62.3 \%$ in 1989 to $65 \%$ in $1995,65.8 \%$ in $2000,66.5 \%$ in 2005 , and to $67 \%$ in 2010.

Assumptions Four scenarios were developed to create a range of future fleet efficiency estimates. The "Base Case" assumes no improvements due to retrofitting and no new, post-2000 generation of aircraft. The "Retrofit" case assumes retrofitting improvements increase $S M_{n}^{D} G$ by $0.5 \% / y r$. The "Post2000 Aircraft" case assumes no retrofitting but accelerated introduction of a new generation of aircraft. Finally, the "Post-2000 Aircraft and Retrufit" case includes both types of efficiency improvements. To introduce post-2000 aircraft into the FAA forecast, we accelerate the scrappage rates of older aircraft or replace the sales of current generation aircraft with post-2000 aircraft. We assume, that beginning in 2005, aircraft older than 20 years are scrapped and replaced with post-2000 generation models. In addition, current generation (not 1990's generation models) sold after 2000 in the FAA forecast are replaced with post-2000 models. 
Even assuming no advanced, post-2000 aircraft and no improvement in the SMPG's of existing airframes, fleet efficiencies will improve from an estimated 49.2 SMPG in 1989 to 64.6 SMPG in 2010 (Table 2). This is an average annual rate of efficiency improvement of $1.31 \%$ and a total gain of $31 \%$. Energy intensity, measured as revenue passenger miles per gallon (RPMPG) increases from 30.6 to 43.3 , an annual rate of $1.66 \%$, and an overall improvement of $41 \%$. Thus, even if virtually nothing is cone beyond the replacement of existing aircraft with newer models, seat-mile efficiency will improve by more than one fourth and passeliger mile efficiency by more than a third. Because of the rapid growth of traffic, however, energy use will increase significantly, from 17.8 billion gallons annually to 26.0 billion (a rate of $1.8 \% / y_{r}$ ).

Making continuous improvements to existing aircraft but introducing no super-efficient, post-2000 models raises SMPG to 71 in 2010 and lowers fuel use to 23.8 billion gallons annually. Introducing post-2000 aircraft but making no improvements to existing airframes raises the 2010 SMPG to 77 , and reduces fuel use to 22.4 billion gallon. Fuel use can be further reduced to 20.9 billion gal uns annually by adding retrofit efficiency improveme ts to new superefficient aircraft. The new models raise the rate of efficiency improvement to $2.1 \%$ to $2.5 \%$.

Advanced aircraft plus continued SMPG improvements to existing models reduce 2010 fuel use by 5.1 billion gallons (0.3 MBD of jet fuel) over the base case. This reduces the annual rate of growth of fuel use a full percent, from $1.8 \%$ to $0.8 \%$. Perhaps more important, with a new generation of post-2000 aircraft fleet efficiencies will continue to increase towards the 110-150 SMPG range as vehicle stock is replaced. In the base case, efficiency improvements are nearing the limit of the best available aircraft by 2010. In the advanced technology case, another $50 \%$ SMPG improvement is on its way as the fleet turns over.

\section{REFERENCES}

[1] Boeing Commercial Airplanes, "Current Market Outlook," Seattle, Washington, February 1989.

[2] Davis, S.C., D.B. Shonka, G.J. Anderson-Batiste, P.S. Hu, 1989. "Transportation Energy Data Book, Edition 10," ORNL-6565, Oak Ridge, Tenuessee.
[3] Ethell, J.L., 1983. Fuel Economy in Aviation, NASA SP-462, National Aeronautics and Space Administration, Washington, D.C.

[4] EXXON Air World, 1987. "Airbuses for the 1990's," vol. 39, no. 3., p. 16.

[5] Fishback, Larry, NASA Lewis Research Laboratory, personal communication, March 30, 1989.

[6] Greene, D.L., 1990. "Energy Efficiency Improvement Potential of Commercial Aircraft to 2010," ORNL-6622, Oak Ridge National Laboratory, Oak Ridge, Tennessee.

[7] McDonnell Douglas, 1989. "Outlook for Commercial Aircraft 1988-2002," Long Beach, California.

[8] Mikkelson, D.C. and G.M. Reck, 1988. "Aircraft Engines-III," EXXON Air World, vol. 40, no. 3, pp. 22-26.

[9] O'Lone, R.G., 1989. "Commercial Airframe Makers Take Conservative Approach," Aviation Wcek and Space Technology, March 20, 1989, pp. 197-199.

[10] Plante, J.A., 1988. "The SIMMOD Airport and Airspace Model," manuscript, Operations Research Office, Federal Aviation Administration, Washington, D.C., December 12, 1988.

[11] Ruffles, P.C., 1989. "Aircraft Engines-IV," EXXON Air World, vol. 41, no. 1, pp. 36-38.

[12] Schmitt, D., 1988. "Airline Aircraft-II," EXXON Air World, vol. 40, no. 3.

[13] Smith, M.G., 1988. "Aircraft Engines-1I," EXXON Air World, vol. 40, no. 3, pp. 20-22.

[14] Swihart, J.M., 1988. "Airline Aircraft-I," EXXON Air World, vol. 40, no. 2, pp. 10-14.

[15] Taylor, W.F., 1988. "Fuels," EXXON Air World, vol. 40, no, 3, pp. 29-30.

[16] U.S. Department of Transportation, Federal Aviation Administration, 1989. "Report to Congress: Status of the U.S. Stage 2 Commercial Aircraft Fleet," August 1989, Washington, D.C.

[17] U.S. Department of Transportation, Federal Aviation Administration, 1989, FAA-APO 89-1, 
"FAA Aviation Forecasts, Fiscal Years 1989-2000," Washington, D.C., March 1989.

[18] U.S. Department of Transportation, Office of Economics, Office of the Assistant Secretary for Policy and International Affairs, 1986. "Aircraft Operating Cost and Performance Report, For Calendar Years 1983 and 1984," Washington, D.C.

[19] Warwick, G. and J. Moxon, 1987. "Propians for the 1990's," EXXON Air World, vol. 39, no. 3, pp. 13-16.

[20] Winer, David, 1989. Personal communication, Federal Aviation Administration, Operations Research Office, Washington, D.C.

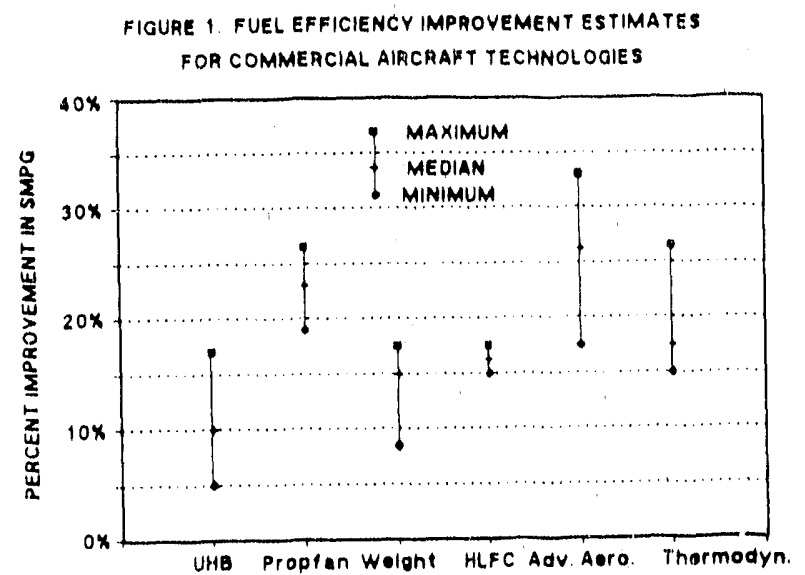

FIQURE 2. COMMERCIAL AIRCRAFT ENEROY EFFICIENCIES

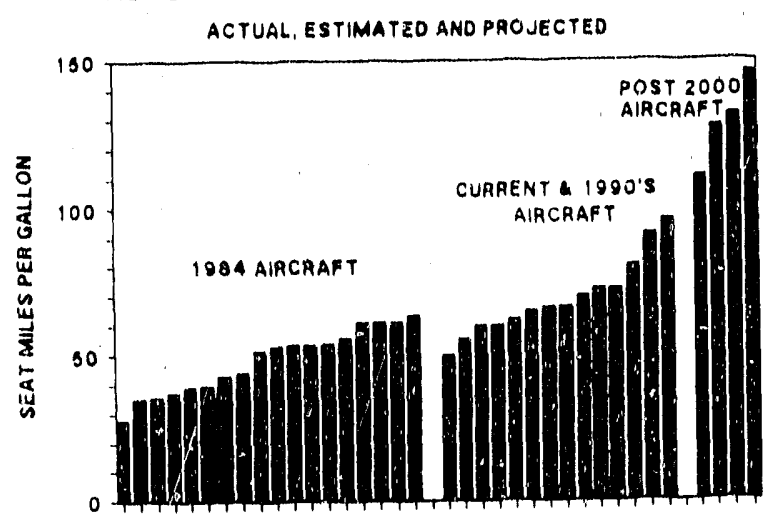

Table 1. Ranges of fifficiency Improwement Polentials for Adranced Toctanatory.

(Percent Improvement in Seat Miles Per Oallon)

\begin{tabular}{|c|c|c|c|c|c|}
\hline & \multicolumn{4}{|c|}{ Technolosy } & \multirow{3}{*}{ Weight } \\
\hline & \multicolumn{4}{|c|}{ Enans } & \\
\hline & $\overline{\mathrm{UHB}}$ & 1 & Propfan & Thermo. & \\
\hline Maximum & 17006 & & $26.5 \%$ & $26.5 \%$ & $17.50 \%$ \\
\hline Median & $10.0 \%$ & & $23.0 \%$ & $17.5 \%$ & $15.0 \%$ \\
\hline Minımum & $5.0 \%$ & & $19.0 \%$ & $15.0 \%$ & $8.5 \%$ \\
\hline
\end{tabular}

\begin{tabular}{|c|c|c|c|c|}
\hline & \multicolumn{2}{|c|}{ Aerodynamis } & \multicolumn{2}{|c|}{$\begin{array}{l}\text { Total Potential } \\
\text { SMPQ Gain } \\
\end{array}$} \\
\hline & $\overline{H L F}$ & $\begin{array}{l}\text { Adv. } \\
\text { Aero. }\end{array}$ & UHB & Propfan \\
\hline Maumum & $17.5 \%$ & $33.0 \%$ & $94.00 \%$ & 103,506 \\
\hline Median & $16.3 \%$ & $26.3 \%$ & $68.8 \%$ & $81.8 \%$ \\
\hline Minimum & $15.0 \%$ & $17.5 \%$ & $+6.0 \%$ & $60.0 \%$ \\
\hline
\end{tabular}

Table 2 Commerctal , wreraft Feet Efrictency and Energy Use Propectiona 1989.2010 .

Sear. Milea Per Gralloo

\begin{tabular}{|c|c|c|c|c|c|c|}
\hline & 1009 & 1998 & 2000 & 2005 & 2010 & $1902 \times 10$ \\
\hline Besc Case , & $\$ 9.2$ & 53.6 & 58.3 & 62.1 & 64.6 & $1.3 \%$ \\
\hline Retroelt & & 55.2 & 61.2 & 66.5 & 0.7 & 1.84 \\
\hline Pou. 2000 & .. & 53.6 & 58.3 & 65.9 & 76.7 & $2.1 \%$ \\
\hline Pou. 3000 \& Ret. & - & 55.2 & 61.2 & 70.2 & 81.9 & $2.5 \%$ \\
\hline
\end{tabular}

Revenue Pawenger Milea Per Ginlloo

\begin{tabular}{|c|c|c|c|c|c|c|}
\hline Base Cane & 30.6 & 44.9 & 38.3 & 41.3 & 43.3 & 1.78 \\
\hline Retrotit & - & 35.8 & $\$ 0.3$ & $\$ .2$ & 47.4 & 210 \\
\hline Pon.2000 & - & 34.9 & 38.3 & 43.8 & $\$ 1.1$ & $25 x$ \\
\hline POAN.2000 \& Ret. & - & 35.8 & 40.3 & $\$ 6.7$ & 54.9 & $2.8 \%$ \\
\hline \multicolumn{7}{|c|}{ Fuel Uso (10 Cralloms) } \\
\hline Basec Cane & 17.8 & 20.7 & 22.6 & 24.1 & 26.0 & $1.8 \%$ \\
\hline Retroces & - & 20.2 & 21.5 & 225 & 23.8 & $1.4 \%$ \\
\hline Pout-2000 & - & 20.7 & 22.6 & 229 & 24 & $1.1 \%$ \\
\hline Poan. $2000 \propto$ Ret. & - & 20.2 & 215 & 215 & 20.9 & $0,8 \%$ \\
\hline
\end{tabular}




\section{DISCL.AIMER}

This report was prepared as an account of work sponsored by an agency of the United States Government. Neither the United States Government nor any agency thereof, nor any of their employees, makes any warranty, express or implied, or assumes any logal liability or responsibility for the accuracy, completeness, or usefulness of any information, apparatus, product, or process disclosed, or represents that its use would not infringe privately owned rights. Reference herein to any specific commercial product, process, or service by trade name, trademark, manufacturer, or otherwise does not necessarily constitute or imply its endorsement, recommendation, or favoring by the United States Government or any agency thereof. The views and opinions of authors expressed herein do not necessarily state or reflect those of the United States Government or any agency thereof. 

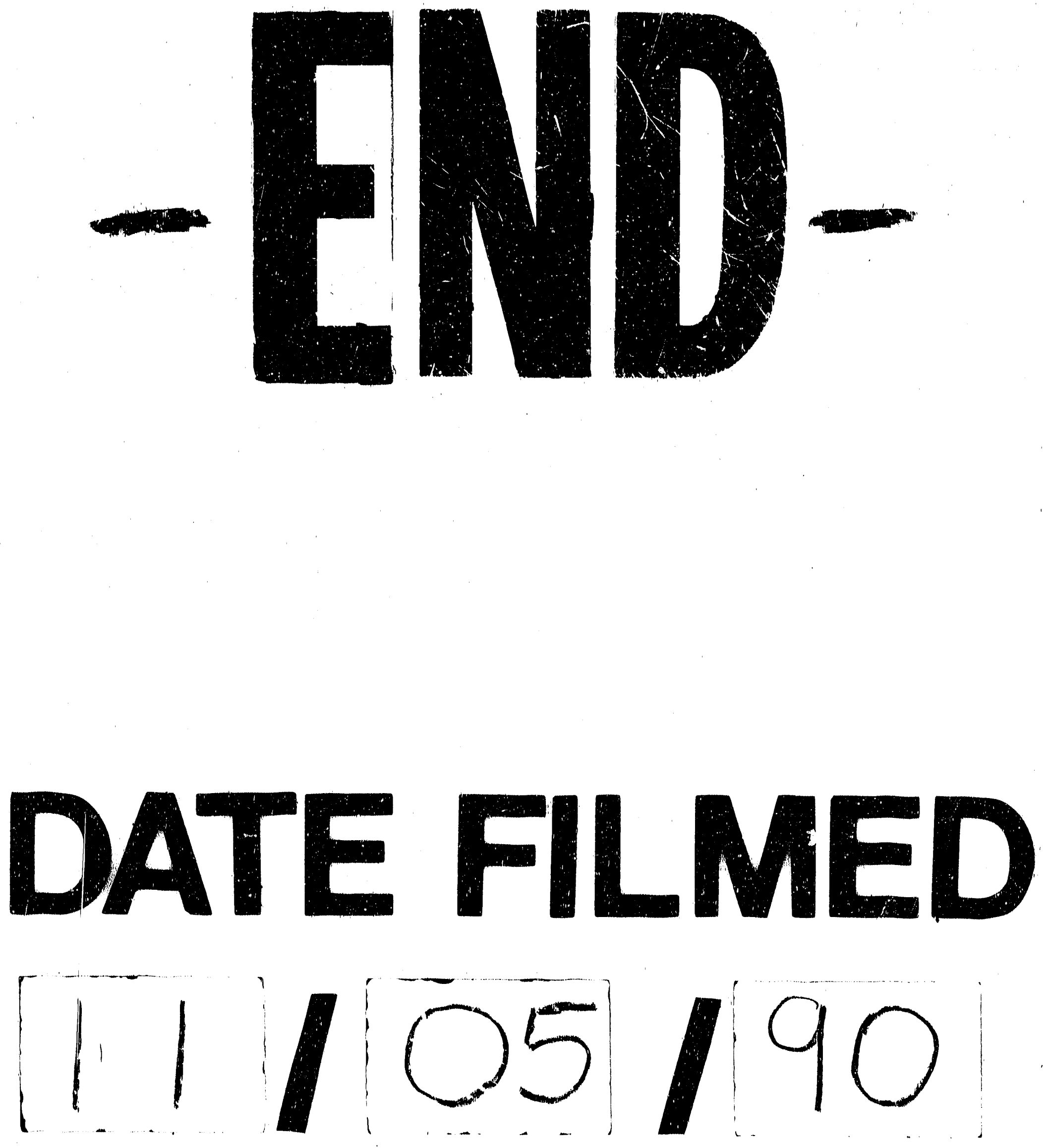
(1) 